\title{
LUGAR-PENSAMENTO INDÍGENA E AGÊNCIA DE HUMANOS E NÃO HUMANOS (A PRIMEIRA MULHER E A MULHER CÉU EMBARCAM NUMA TURNÊ PELO MUNDO EUROPEU!) ${ }^{1}$
}

\author{
VANESSA WATTS-POWLESS ${ }^{2}$ \\ QUEEN'S UNIVERSITY, CANADA
}

\begin{abstract}
Resumo: Esse artigo irá examinar, desde um ponto de vista indígena, como a agência circula através de mundos humano e não humano na criação e manutenção da sociedade. Através de processos de colonização, a corrupção das categorias essenciais de concepção indígena do mundo (feminino e território) resultou na descontinuidade da manifestação da agência nas sociedades indígenas. Através de uma comparação entre o divisor epistemológico-ontológico e a concepção indígena de Lugar-Pensamento, esse artigo argumentará que a agência foi erroneamente tornada uma exclusividade dos humanos, removendo assim a agência não humana do que constitui uma sociedade. Isso foi alcançado, em parte, através da "mitologização" das histórias indígenas de origem e da separação da comunicação, da formalização de tratados e acordos históricos que os seres humanos mantiveram com o mundo animal, o mundo dos céus, o mundo dos espíritos etc. Para operacionalizar-se, o colonialismo deve tentar colocar em descrédito os povos indígenas e suas histórias. Esse artigo tenta reafirmar a conexão sagrada entre lugar, não humanos e humanos num esforço por alcançar a "mente pré-colonial".
\end{abstract}

PALAVRAS-CHAVE: agência; epistemologia; ontologia; território; mulheres indígenas.

ABSTRACT: This article will examine how agency is circulated through human and nonhuman worlds in the creation and maintenance of society from an Indigenous point of view. Through processes of colonization, the corruption of essential categories of Indigenous conceptions of the world (the feminine and land) has led to a disconnect between how this agency is manifested in Indigenous societies. Through a comparison between the epistemological-ontological divide and an Indigenous conception of Place-Thought, this article will argue that agency has erroneously become exclusive to humans, thereby removing nonhuman agency from what constitutes a society. This is accomplished in part by mythologizing Indigenous origin stories and separating out communication, treaty-making, and historical agreements that human beings held with the animal world, the sky world, the spirit world, etc. In order for colonialism to operationalize itself, it must attempt to make Indigenous peoples

\footnotetext{
${ }^{1}$ Publicado originalmente em Decolonization: Indigeneity, Education \& Society 2(1), 2013:20-34. Traduzido por Loredana Ribeiro com autorização da autora.

${ }^{2}$ Vanessa é Mohawk e Anishnaabe, do Clã Urso. Atualmente finaliza seu doutorado em Sociologia pela Queen's University, no Canadá. Tem graduação em Estudos Nativos pela Trent University e mestrado pelo Programa de Governança Indígena da University of Victoria, ambas no Canadá. Vanessa vive com seu marido perto do Grand River em Brantford, Ontário, feliz por estar perto de sua casa e família enquanto trabalha na McMaster University. Ela traz sua experiência como estudante, ex-conselheira acadêmica e conselheira estudantil no Programa de Estudos Indígenas para sua atuação como professora assistente em dedicação exclusiva (https://cms-socsci.mcmaster.ca/IndigenousStudies/people-1/wattsv).
} 
stand in disbelief of themselves and their histories. This article attempts to reaffirm this sacred connection between place, non-human and human in an effort to access the "pre-colonial mind".

KEYWORDS: agency; epistemology; ontology; land; Indigenous women.

\section{Introdução}

De acordo com os Haudenosaunee, a Mulher Céu caiu por um buraco no céu. John Mohawk (2005) descreve sua jornada em direção às águas abaixo. Em sua queda, a Mulher Céu caiu através das nuvens e do ar em direção às águas abaixo. Durante sua queda, os pássaros puderam ver essa criatura em queda e ver que ela não podia voar. Eles foram até ela e a ajudaram a desacelerar sua queda até as águas abaixo dela. Os pássaros disseram à Tartaruga que ela precisava de um lugar para pousar, já que ela não tinha nadadeiras. A Tartaruga emergiu, subindo à superfície das águas de modo que a Mulher Céu pudesse pousar em suas costas. Uma vez sobre a Tartaruga, a Mulher Céu e a Tartaruga começaram a formar a Terra, e a terra é uma extensão de seus corpos.

Entre os Anishnaabe, uma história similar é contada. Leane Simpson (2011) conta a História de Criação Anishnaabe, a partir do sistema histórico dos Sete Fogos da Criação. Os dois fogos que eu gostaria de relacionar a esta idéia de Lugar-Pensamento são o Quinto Fogo e o Sexto Fogo. No Quinto Fogo, Gizhe-Mnidoo (o Criador), colocou seus pensamentos em sementes. No Sexto Fogo, Gizhe-Mnidoo criou a Primeira Mulher (Terra), um lugar onde estas sementes poderiam criar raízes e crescer.

Antes de continuar eu gostaria de enfatizar que esses dois eventos aconteceram. Eles não foram imaginados ou fantasiados. Isso não é um conto, mito ou lenda. Estas histórias não são longas versões de um "e a moral da história é...". Isso é o que aconteceu.

Às vezes, essas histórias de criação gastam dias para serem descritas. Para os propósitos desse artigo, eu gostaria de focar em uma 
compreensão histórica comum sobre a origem da espécie humana - o espiritual e o feminino. Esses relatos históricos, dois de muitos, falam das intersecções comuns entre feminino, animal, mundo dos espíritos e mundos minerais e vegetais. O que constitui "sociedades" nessas perspectivas gira em torno de interações entre esses mundos mais do que apenas de interações entre humanos. Esses dois relatos descrevem um entendimento teórico do mundo via incorporação física - LugarPensamento. Lugar-Pensamento é o espaço não distintivo onde lugar e pensamento nunca estiveram separados, porque eles nunca puderam ou podem ser separados. Lugar-Pensamento se embasa na premissa de que o território está vivo e pensando, e que humanos e não humanos derivam sua agência das extensões desses pensamentos.

Isso posto, percepções indígenas sobre quem, ou o que, contribui para uma estrutura social são bem diferentes do pensamento tradicional euro-ocidental. A avaliação da cultura e intenção humana tem sido uma preocupação da sociologia tradicional desde sua concepção e levou à definição do que constitui uma sociedade em diferentes sociedades. A ideia de "sociedade" tem girado em torno dos seres humanos e de seu lugar especial no mundo, dadas suas capacidades de razão e linguagem. Mesmo que esta ideia de sociedade ainda seja amplamente atribuída às relações humanas, recentemente podemos ver a emergência de não humanos sendo avaliados em termos de suas contribuições para o desenvolvimento e manutenção da sociedade.

Esse artigo irá examinar como a agência circula dentro de dois modelos diferentes: Lugar-Pensamento (cosmologias haudenosaunee e anishnaabe) e epistemológico-ontológico (quadro euro-ocidental). Minha intenção é tanto enfatizar o diferente enquadramento das cosmologias indígenas quanto examinar nossas ricas e inteligentes teorias, encontradas nessas cosmologias.

Como uma mulher haudenosaunee e anishnaabe, minha visão de mundo é continuamente posta à prova contra o modelo colonial. É, portanto, uma tarefa importante imaginar e buscar por nossos ensinamentos originais, localizados naquilo que Susan Hill (2011) chama de "mente pré-colonial". Dado esse constante conflito, é necessário identificar quais poderiam ser as intenções da terra, e como ela tentaria falar conosco. 


\section{Reivindicando nosso modelo}

Nossos entendimentos do mundo são comumente vistos como "míticos" pela sociedade moderna, enquanto nossas histórias são consideradas modos alternativos de compreensão e interpretação, ao invés de eventos "reais". Colonização não é um ataque apenas às pessoas e aos territórios, mais que isso, esse ataque é consumado em parte através de uma ignorante e proposital deturpação das cosmologias indígenas. Para demonstrar isso, examinemos como a Primeira Mulher (Terra) e a Mulher Céu são interpretadas através de um divisor epistemológico-ontológico estrangeiro.

Estruturas são modelos de entendimento e interpretação. São a base de como humanos se organizam politicamente, filosoficamente etc. Num sentido euro-ocidental, as estruturas existem de modo abstrato. O modo como se articulam em ação e comportamento trazem essa abstração à praxis; daí a divisão entre epistemológico/teórico versus ontológico/praxis. A diferença nas estruturas haudenosaunee e anishnaabe é que nossas estruturas cosmológicas não são abstrações, mas uma extensão literal e animada dos pensamentos da Mulher Céu e da Primeira Mulher; é impossível separar a teoria da praxis se acreditamos nos eventos históricos de criação da Mulher Céu e da Primeira Mulher. Então não é que os povos indígenas não teorizem, mas essas teorias complexas não são diferenciadas do lugar.

Abaixo segue uma representação visual destas duas estruturas. À esquerda temos um esboço de como uma cosmologia anishnaabe e/ou haudenosaunee pode ser representada. À direita, o processo pelo qual a metacompreensão euro-ocidental pode contribuir para a colonização destas cosmologias indígenas: 

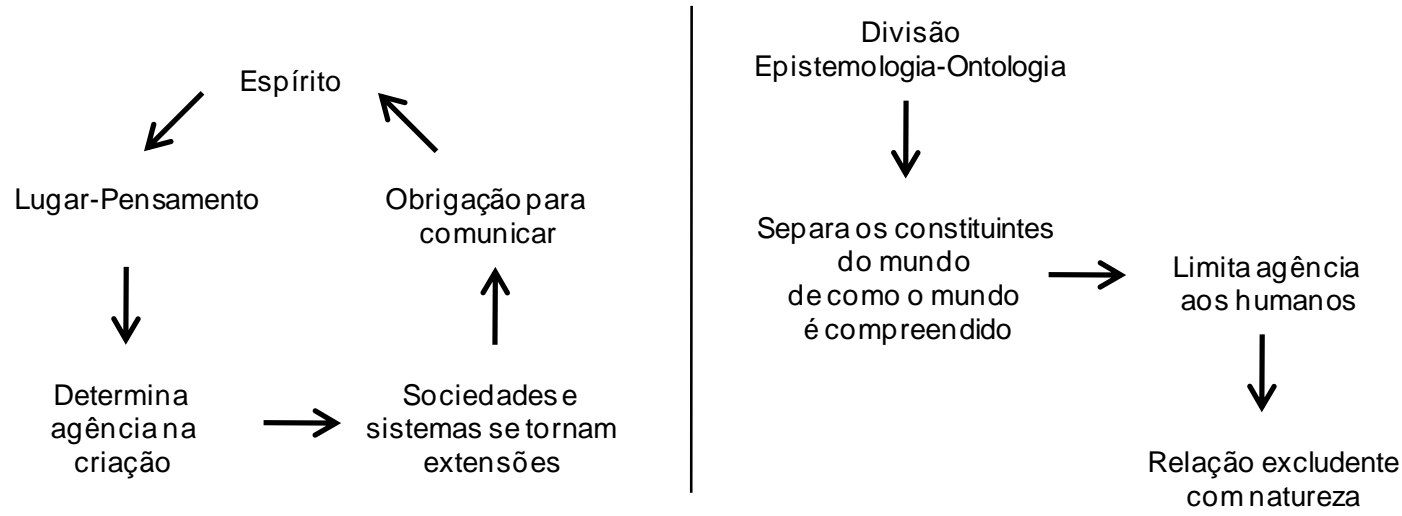

Figura 1.1

A figura acima não tem a pretensão de ser um modelo universal de como todos os povos indígenas pensam, acreditam etc. Ao contrário, é um simples esboço das diferenças cruciais entre os processos indígenas e euro-ocidentais. O visual da esquerda descreve a natureza animada do território. Ser animado vai além de estar vivo ou agindo, é estar repleto de pensamento, desejo, contemplação e vontade. É a concretização literal do feminino, da Primeira Mulher, na qual muitas histórias de criação indígenas encontram sua origem. Quando a Mulher Céu cai sobre as costas de uma tartaruga, ela não se torna apenas capaz de criar terra, mas se torna o próprio território. Portanto, LugarPensamento é uma extensão de sua condição, desejo e comunicação com as águas e os animais - sua agência. Através dessa comunicação ela é capaz de se tornar a base sobre a qual todas as futuras sociedades serão construídas - terra.

Tornando-se terra ou território, ela se torna o designador de como todos os seres vivos irão se organizar sobre ela. Onde as águas fluem e se acumulam, onde montanhas surgem e formam vales, todos se tornam demarcações de quem residirá onde, como irão viver e determinam como se comportarão uns em relação aos outros. Cientistas se referem a isso como ecossistemas ou habitat. Entretanto, se aceitarmos a ideia de que todos os seres vivos possuem um espírito, então isso se estende para além de complexas estruturas dentro de um ecossistema. Significa que seres não humanos escolhem como irão residir, interagir e estabelecer relações com outros não humanos. Então, todos os elementos da natureza possuem agência e essa capacidade não é limitada por ações inatas ou relações causais. 
Assim, de um ponto de vista indígena, ecossistemas e habitat são melhor entendidos como sociedades; o que significa que eles possuem estruturas éticas, tratados e acordos interespecíficos, além da capacidade de entender, interpretar e implementar. Seres não humanos são agentes da sociedade. Não apenas são ativos, como também influenciam diretamente a maneira como os humanos se organizam naquela sociedade. A própria existência dos sistemas clânicos evidencia esses muitos acordos históricos entre humanos e não humanos. Sistemas de clãs variam de comunidade para comunidade e são amplamente dependentes da paisagem circundante. Por exemplo, clãs baleias não estão presentes entre nações indígenas onde não existe acesso a águas marítimas. A estrutura das sociedades é demarcada pelo território, que, mais uma vez, é uma extensão da circunstância original da Mulher Céu. Ela está presente nas relações entre humanos e humanos, humanos e não humanos e entre não humanos e não humanos.

A ação e o pensamento humanos são assim derivados de uma expressão literal de lugares particulares e eventos históricos nas cosmologias haudenosaunee e anishnaabe. A agência que o lugar possui pode ser pensada de maneira similar à agência que os pensadores ocidentais atribuem aos seres humanos. Disso segue que se, como povos indígenas, nós somos extensões da própria terra sobre a qual caminhamos, então nós temos a obrigação de manter a comunicação com ela. Um alerta familiar é ecoado em muitas comunidades, dizendo que se não cuidarmos da terra corremos o risco de perder quem nós somos como povos indígenas. Quando esse aviso é examinado sob os termos do Lugar-Pensamento original, não nos arriscamos apenas aos perigos de uma perda de identidade ou deslocamento físico, mas também a nossa capacidade de pensar, agir e governar se torna comprometida, porque essa relação é continuamente corrompida por imposições externas de como a agência é organizada. A colonização cessou nossa capacidade de comunicação com o lugar e pôs em perigo a agência entre as populações indígenas. A mente pré-colonial foi confrontada com uma agência diminutiva e o processo pelo qual garantimos nossa própria habilidade de interagir e conversar com não humanos e outros humanos ficou comprometido. A interrupção desse 
processo original vai além da perda de uma forma de identidade ou visão de mundo indígena e como elas são praticadas - se torna uma violação da intencionalidade da Mulher Céu.

O divisor epistemológico-ontológico processa a agência de uma maneira muito diferenciada. $O$ entendimento comum de epistemologia descreveria que a percepção que alguém tem do mundo é distinta do que existe no mundo ou o constitui (DESCARTES, 1996). Pensamentos e idéias são reservados àqueles que percebem - humanos. Todos os outros objetos, actantes ou seres do mundo podem ter uma essência (KANT, 1999; LATOUR, 1987) ou uma interconexão com humanos, mas suas habilidades de perceber são nulas ou limitadas a reações instintivas.

O epistemológico-ontológico remove o "como" e o "por que" do "quê". O "quê" é deixado vazio, pronto para preenchimento. Epistemologia tem muitas representações: a ciência, o cristianismo, o eurocentrismo, o marxismo, o comunismo etc. Ontologia também contém muitas variáveis: os objetos possuem uma essência? O que existe no mundo e como suas partes formam uma sociedade? Todas estas preocupações são, por suas naturezas, temas do questionamento humano baseado em uma capacidade de racionalização. Esses domínios distintos apresentam evidências de que os humanos são assumidos como separados do mundo que habitam, de modo a terem uma percepção dele (KANT, 2008) ${ }^{3}$. Essa é uma estrutura teórica de entendimento do mundo e seus constituintes. São necessárias não apenas uma separação entre humanos e não humanos, como também uma hierarquia dos seres em termos de como esses seres são capazes de pensar.

A distinção artificial entre o "quê" e o "como/por que" não é uma distinção inocente. Suas consequências podem ser desastrosas não apenas para não humanos como para os humanos também. Se sobrepusermos esse quadro à natureza, a humanidade é colocada para fora ou mesmo acima do mundo natural. O raciocínio é que a percepção é um dom ou um traço com o qual apenas a mente humana fora agraciada, e certamente algo que uma pedra ou um rio não possuem.

\footnotetext{
${ }^{3}$ Para mais informações, favor consultar a argumentação sobre sujeito-objeto da revolução copernicana de Immanuel Kant em sua obra Crítica da Razão Pura.
} 
Um rio pode agir (ou seja, fluir), mas ele percebe, ou contempla isso? A perspectiva anishnaabe responderia com uma afirmativa. Como podemos ver através do processo de colonização e a imposição do modelo epistemológico-ontológico, nossa comunicação e nossas obrigações com outros seres da criação são continuamente interrompidas.

Por exemplo, na história de criação cristã, vemos como a interação entre feminino (Eva) e não humanos (a Serpente, a Árvore do Conhecimento, a maçã) levou à condenação de toda a humanidade futura (Ah, aquela mulher enxerida!). Também significa que o jardim, onde eles antes podiam residir, rapidamente se tornou um local de onde a humanidade foi expulsa. Ela já não estava no entorno, mas fora dele. Esse resultado tem muitas consequências, duas delas significantes para os propósitos desse artigo.

Primeiramente, os humanos foram colocados num mundo onde eram capazes de sobrepujar a natureza. Em segundo lugar, e de maneira interdependente, os humanos decidiram que a comunicação com a natureza carrega efeitos desastrosos (a Árvore do Conhecimento, a Serpente) e assim a comunicação interespecífica tornou-se bastante limitada, senão profana. Nessa visão de mundo, a agência associou-se às interações humano-humano. Sociedades foram erigidas sobre a dominação da natureza com base na ideia de que acordos entre humanos e o mundo animal eram desnecessários, senão perigosos. De uma perspectiva indígena, por outro lado, a mesma interação entre feminino e não humano teve resultados diferentes. Para muitos povos indígenas, estar alinhado com o mundo animal é uma posição tratada com honra e respeito (SIOUI, 1992). Esse paradoxo relacional criou um ponto de devastação, onde nossos elementos mais sagrados (terra e mulheres) foram violentamente corrompidos com uma falsa profanação.

Inversamente, em muitas histórias indígenas de criação, a ideia de que os humanos foram a última espécie a chegar à Terra é central; o que também significa que os humanos chegaram numa condição de dependência, em uma sociedade já em funcionamento com valores particulares, éticas particulares etc (BENTON-BENAI, 2010). A inclusão dos humanos nessa sociedade tornou necessário que certos acordos, acertos etc. fossem feitos com o mundo animal, o mundo vegetal, o 
mundo dos céus, o mundo mineral e com outras espécies não humanas. Portanto, estar associado aos animais, seja através de sistemas clânicos, cerimônias, ou de seres que agem como conselheiros, revelou-se uma posição de reverência. Na história de criação haudenosaunee, a Mulher Céu ficou curiosa e caiu por um buraco no céu e foi trazida com segurança até a terra por diferentes pássaros que a pousaram nas costas de uma tartaruga. Com a ajuda de outros animais eles foram capazes de criar o território e o princípio da humanidade.

Tanto a história do Gênesis quanto a história da Mulher Céu falam sobre um mundo que existiu antes dos humanos. Ambos contam a interação entre uma mulher e não humanos que causou impactos significativos na criação e na humanidade. No último, a relação entre animais e feminino é considerada sagrada e foi ritualizada por gerações. Esta relação também se tornou fundacional para futuros sistemas de clãs, ética, governança, cerimônias etc. No primeiro, o feminino se tornou responsável por todas as dores do parto e ressentimentos pela expulsão do paraíso. A interação entre Eva e a Serpente resultou em vergonha e excomunhão da natureza. Ainda, diálogos e comunicações futuras com animais se tornaram tabu e fonte de bruxaria. É nesse ponto de conflito que pensamento, percepção e ação são separados da suposta inércia da natureza.

\section{Governança, agência e não humanos}

Se partimos da premissa de que a terra é feminina e, além disso, de que ela pensa, então ela está viva. Se a fêmea elementar é concebida como responsável por dor, vergonha e excomunhão, então destruí-la não parece tão ruim. De fato, talvez ela inclusive mereça sofrer violência. Afinal, sua natureza curiosa comprometeu a vida que os seres humanos poderiam ter tido, mas não puderam experimentar por causa de suas ações irresponsáveis - por conseguinte, a base do ressentimento. Qualquer obrigação de empatia com ela é desnecessária porque essa visão de mundo dominante ensina que feminino é sinônimo de desapontamento e estupidez. Não é nenhuma surpresa, então, que em uma construção euro-cristã a terra e as suas designações sejam 
silenciadas. Muitos povos indígenas se espantam com o quanto de destruição pelo colonizador tem persistido ao longo das décadas, sem qualquer tentativa significativa de detê-la. Se você pertence a uma estrutura onde terra e feminino são não apenas inferiores, mas reconhecidamente irresponsáveis, violações contra elas parecem garantidas.

Ao pensar em agência tendo por referência o Lugar-Pensamento, onde ela pode ser encontrada? Eu a encontro em animais, em humanos, em plantas, em rochas etc. Em primeiro lugar, como cheguei a pensar que estas diferentes entidades e seres tinham agência? A partir de fábulas/histórias [story/history]. Por exemplo, um evento ocorreu, talvez, entre um urso e uma jovem mulher, e desse encontro surgiu uma ideia sobre um sistema de clãs. Ou talvez Três Irmãs, nomeadas Milho, Feijão e Abóbora, decidiram fazer um acordo sobre como elas viveriam juntas. Talvez pareça que eu estou contando fábulas, mas eu realmente estou comentando dois exemplos de eventos históricos que ocorreram em um determinado local, em um momento particular, onde a consciência, pensamento, desejo e imaginação de todos os envolvidos estavam em ação.

Em uma estrutura epistemológica-ontológica, cosmologias indígenas seriam exemplos de uma interconectividade simbólica - uma abstração de um código moral. Seriam uma maneira de ver o mundo a base para uma orientação epistemológica. A partir da visão de mundo haudenosaunee, isso é o que aconteceu. Além disso, nos sistemas haudenosaunee, pessoas, territórios etc. são afetados por esta relação entre as Três Irmãs. Isso é mais que uma lição, um ensinamento ou até mesmo um relato histórico. Seu acordo consciente se estende diretamente a nossas filosofias, pensamentos e ações como pessoas haudenosaunee.

Cada vez mais esses tipos de eventos históricos indígenas (Mulher Céu, as Três Irmãs) são não apenas aceitos por estruturas ocidentais de compreensão, mas procurados em termos de interfaces não opressivas e provocativas ou interessantes de acesso ao real. Isso traça os povos indígenas não só como epistemologicamente distintos, mas também como uma porta de entrada para os pensadores não indígenas reimaginarem seu mundo. Nesse movimento, nossas histórias são muitas 
vezes destiladas para simplesmente isso - palavras, princípios, morais para imaginar o mundo e nos imaginar no mundo. Nessa leitura de fábulas, os povos não indígenas ainda mantêm controle sobre o que é agência e como ela se dispersa nas mãos de humanos.

Ao longo do tempo e através de processos de colonização, as fronteiras corporais e teóricas da divisão epistemológica-ontológica contribuíram com as interpretações coloniais de natureza/criação que atuam para centralizar o humano e deslocar a natureza à periferia em uma relação de exclusão. Terra torna-se dimensionada e modificada em termos de progresso e avanço. Historicamente, a medida da interação colonial com a terra tem sido de violência e individualizações demarcadas, onde a terra está para ser explorada, não para aprendermos com ela e sermos parte dela. Por outro lado, o ancião anishnaabe Fred Kelly (2006) afirma:

Se você ouvir a nossa história da Criação, nós invariavelmente aterramos nas costas de uma tartaruga. Por que, no nosso caso, a chamamos Ilha da Tartaruga? Bem, esta é a ilha onde fomos colocados, mas além disso, para demarcá-la, a avó que ilumina o céu noturno, comumente ou coloquialmente chamada Lua, em sua glória total sai treze vezes por ano quatro estações. Não doze - treze vezes. Isso acontece quando ela beija a Tartaruga... Olhe agora para a tartaruga. Conte as plaquetas nas costas de uma tartaruga. Treze. É por isso que nós a chamamos de Ilha da Tartaruga. Agora, a diferença desses conceitos com a legislação euro-canadense são os conceitos de propriedade e de direitos de propriedade. Enquanto os euro-canadenses falam sobre direitos de propriedade, nós falamos de território. Esta é a relação mais estreita. E é a relação com a Mãe Terra. Assim, se você entende a Lei Sagrada e a Grande Lei, que são parte integrante da Avó Terra, então é concebível que você possa vendê-la? Em primeiro lugar, vendê-la equivale a vender-se. Você pode fazer isso? Não sob a Grande Lei, não sob a Lei Sagrada. Assim, você não pode vender sua avó. Isso simplesmente não é permitido. Deixe-me colocar de outra forma: é inconstitucional. É contra a lei - é ilegal. Assim, no direito indígena, não é possível vender qualquer parte da Avó Terra, porque temos uma relação sagrada com ela. Nós somos uma parte dela (KELLY, 2006, p. 11). 
Nossa verdade, não só dos povos Anishnaabe e Haudenosaunee, mas da maioria das sociedades indígenas, é que nós (humanos) somos feitos de terra; nossa carne é literalmente uma extensão da terra. A terra é entendida como feminina: Primeira Mulher designou o início do mundo animal, do mundo das plantas e dos humanos. Foi a própria feminilidade da terra que instituiu todos os seres como corporificações literais de significados localizados (TRASK, 1999; PESANTUBBEE, 2007). Em nossa compreensão de como a vida começou (vida dos seres humanos), é aceito que as criaturas, a terra e o planeta já existiam muito antes de nós. Poderia Lugar-Pensamento ser a rede na qual seres humanos e não humanos se relacionam, traduzem e articulam a sua agência? Se eu, como humana, sou feita do material do solo e do espírito, eu não estendo para o mundo não humano nada além de interações causais? E o que, nesses relacionamentos não humano-nãohumano, demarca vários papéis e responsabilidades dos humanos?

Se nós partimos da premissa de que de fato somos feitos da terra, então nossos princípios de governança estão refletidos na natureza. Sharon Venne (1998) escreve:

\begin{abstract}
Nossa espiritualidade e nossas responsabilidades definem nossos deveres. Entendemos o conceito de soberania como entrelaçado num tecido que engloba nossa espiritualidade e responsabilidade. Esta é uma visão cíclica da soberania, incorporando-a em nossa filosofia tradicional e visão de nossas responsabilidades. É muito diferente do conceito de soberania ocidental, que se baseia no poder absoluto. Para nós, poder absoluto está no Criador e na ordem natural de todos os seres vivos; não apenas nos seres humanos... Nossa soberania está relacionada com nossas conexões com a terra e é inerente. A ideia de nação não se aplica apenas a seres humanos. Nós chamamos de nação os búfalos ou os lobos, os peixes, as árvores, e todos mais. Cada uma é soberana, uma parte igual da criação, interdependente, entrelaçada, todos estão relacionados (VENNE, 1998, p. 23).
\end{abstract}

Kaagoogiiwe-enaakoonige ("Lei Sagrada", em anishnaabe) se traduz literalmente como "a decisão circular de eterna importância" (KELLY, 2006). A terra feminina, ou o feminino, está intrinsecamente ligada à noção de soberania e de como os humanos interagem com 
criaturas não humanas na formação de governança. A descrição de Venne de soberania como atada à responsabilidade ou obrigação com os ensinamentos originais da terra empresta a essa ideia a noção de que o feminino não é apenas respeitado, mas é visto como fonte de poder e conhecimento. A soberania não é apenas uma ideia contestada (localizada em uma epistemologia); em vez disso, é uma obrigação essencial para a continuação de nós mesmos. Por outro lado, essa fonte de poder é muitas vezes concebida como parte de sistemas de conhecimento subjugados por categorizações ocidentais de hierarquia. Então o que acontece quando o centro todo-poderoso tenta criar um espaço dessubjugado via interações não humanas?

\section{Uma agência subjugada por não humanos}

Porque a terra é tão vital para a formação de sociedades indígenas e para o funcionamento dos seres humanos, eu quero explorar como esse elemento é tratado em termos de agência por pensadores não indígenas - especificamente nos estudos da ciência e nos ecofeminismos. Ambos os discursos são considerados progressivos por introduzir o papel dos não humanos no pensamento euro-ocidental. Por exemplo, a Teoria do Ator-Rede de Bruno Latour (1987) é construída sobre a premissa de interconexão de cadeias referenciais de humanos e não humanos e no modo como essas conexões identificam troca/efeito mútuos.

Em Saberes Localizados, Haraway (1988) tenta implodir o centro onde a produção de conhecimento (epistemologia) é geralmente baseada no heteropatriarcado. Seu trabalho contribui com uma valiosa discussão sobre como os conhecimentos localizados, que ela associa com povos subjugados, proporcionam um espaço onde as fronteiras dominantes desse heteropatriarcado podem ser implodidas. No entanto, Haraway resiste a noções essencialistas da terra como mãe ou matéria e em vez disso escolhe utilizar produtos de conhecimentos localizados (o Coiote ou o Embusteiro) como um processo de implosão de fronteiras: "Gosto de pensar na teoria feminista como o discurso do coiote reinventado, devedor de suas fontes de possibilidade nos muitos tipos 
de explicações heterogêneas do mundo" (HARAWAY, 1988, p. 594). Esse é, mais uma vez, um nível de engajamento abstrato. Embora possa servir para alterar as tendências imperialistas na produção de conhecimento euro-ocidental, histórias indígenas ainda são consideradas como fábula e processo - uma ferramenta de distanciamento do Ocidente.

Não estou afirmando que pensadores euro-ocidentais são inerentemente coloniais. Em vez disso, a distinção epistemológicaontológica é muitas vezes a base pressuposta na qual argumentos euroocidentais são apresentados. É esse pressuposto que, argumento, cria espaços para ocorrência de práticas coloniais. Podemos ver como o pensamento euro-ocidental está começando a abraçar contribuições do mundo não humano; no entanto, o elemento controverso da agência é frequentemente redesenhado quando aplicado a não humanos, mantendo assim intacta a divisão epistemológica-ontológica.

Alaimo (2008) descreve o seguinte:

O pó mostra uma agência sem agentes, um fundacional, perpétuo devir que acontece sem vontade ou intenção ou delimitação. Na verdade, o pó, uma substância bastante indiscreta, é necessário para o surgimento de formas de vida menos difusas (ALAIMO, 2008, p. 247).

Desse modo, o pó atua. Ele não necessariamente pensa, nem quer ou deseja, mas está constantemente cumprindo sua intenção. Ele é necessário para a sobrevivência de outras formas de vida; ele fornece um espaço para a vida surgir. No entanto, esse tipo de agência é hierárquico; é dependente da crença de que os humanos são diferentes de acordo com a nossa capacidade de vontade e propósito. Pó é reconhecido, na melhor das hipóteses, como actante, não mais uma reflexão tardia, mas ainda limitado no que diz respeito à capacidade. Como o pó me afeta? Como faço para afetar o pó? Estas são as perguntas que sublinham a agência limitada a um dilema humanocêntrico.

Alaimo afirma, ainda, que o pó não pode ser elevado ao status de "membro da família", mas pode ser pelo menos elevado a "algo digno de cuidados e nutrição" (2008, p. 254). Consumo, propriedade etc. são 
conceituados como a base para a transcorporeidade no processo pelo qual as fronteiras são construídas e solidificadas. Nesta relação com o pó, os seres humanos são responsáveis pela terra da forma como o dono pode ser responsável por seu animal de estimação. Esse tipo de terra não é Primeira Mulher; é um brinquedo pedindo atenção.

Vicky Kirby (2008) vai mais longe em sua compreensão do pó e agência, afirmando: "[...] é evidente que natureza/o corpo/materialidade antecedem cultura/intelecto/abstração e, além disso, que o próprio eu pensante não é uma articulação de intenções da matéria" (KIRBY, 2008, p. 216). Kirby insiste no dualismo cartesiano particular onde o intelecto humano e a intencionalidade são distintivos do corpóreo. Não é que um não seja dependente do outro, pois se os seres humanos não tivessem carne, eles não teriam corpo e, portanto, não possuiriam a capacidade de intelectualizar. No entanto, Kirby argumenta que o intelecto, ou o que constitui cultura, está além do corpo e está, portanto, distintamente além do primordial. Esta conceituação subestimada de natureza e cultura é uma problemática que tem sido recodificada no discurso repetidamente - que os seres humanos são exclusivamente distintos da natureza devido a suas capacidades. Interação é permitida, mas apenas enquanto distinção entre o ser humano pensante e o mundo natural atuante. É verdade que os limites da carne e do solo se esfregam uns contra os outros, mas isso não significa que um seja guiado pelo outro. A fronteira onde começa o humano-como-centro ainda existe e continua a determinar os limites de capacidade e ação.

$\mathrm{O}$ interessante é que Kirby conclui que é perigoso anexar ação à causa natural, porque isso leva a um detrimento da singularidade dos humanos e de fato perpetua um continuum de "progresso" em vez de bolsões/locais de agentes politicamente dispostos. Ela escreve:

Determinações naturais parecerão um retorno prescritivo para algo do passado, algo inegável e imutável. No primeiro caso, quando explicamos nossos pensamentos e ações como produtos e efeitos culturais, também estamos enfatizando que somos agentes ativos em nossos destinos políticos. Ao abraçar a noção de causa e determinação natural, no entanto, corremos o risco de reduzir o que parece tão especial sobre a condição humana ao acaso evolucionário ou ao capricho da natureza (KIRBY, 2008, p. 217). 
É verdade que a causa e a determinação natural na história colonial euro-ocidental agiram para racionalizar e justificar a violência em massa, racismo biológico, sexismo e aculturação. São essas consequências do colonialismo que têm propagado formas de opressão racistas e violentas, encerrando a brancura no centro. Desmantelar essas ideias permite questionar o dominante e separá-lo, de modo que ideologias hegemônicas concentradas tornem-se difusas nos espaços onde limites e fronteiras são confusos e permeáveis. Entretanto, a reivindicação de Kirby da peculiaridade dos humanos para além das determinações naturais desconsidera as concepções indígenas de humano e natureza e, ao mesmo tempo, implica que causa natural e determinismo são aleatórios e, portanto, não intencionais.

Da mesma forma, nos estudos das ciências, muitos estudiosos começaram a redefinir agência para resolver o problema da dicotomia homem/natureza. Por exemplo, a Teoria do Ator-Rede de Bruno Latour (1987) é construída sobre a premissa da interconexão de cadeias referenciais e a troca/efeito mútuo é garantida ao mundo não humano. De modo similar, Nash (2005) afirma que se a agência se deslocou da mente onde o pensamento e a vontade residem, então a agência pode ser concedida aos não humanos. Já Lockie (2004) argumenta que, se agência não inclui consciência ou pensamento, mas que de fato esses atributos estão localizados nas relações entre dois indivíduos, então todo mundo e todas as coisas podem possuir agência em algum nível. Não obstante, mais uma vez o problema da agência subjugada permanece redefinido. Essas interpretações da agência localizam humanos e não humanos em uma rede interconectada de causa e efeito, onde o plano de ação é equalizado entre todos os elementos. Agência, no entanto, atua fora, dentro e nos entremeios desta rede, através de definições cuidadosamente redesenhadas, onde os seres humanos possuem algo mais ou algo especial.

Esses níveis de agência são um produto do paradigma epistemologia-ontologia. Embutido nele, como demonstrado, está a ideia de propriedade do humano sobre as coisas não humanas, seres etc. A inclusão do não humano, nesse caso pó/solo, tem sido causal ou instintiva na natureza. $O$ que significa que, embora tenha sido 
concedida a entrada do pó/solo na rede humana de ação, ele ainda é relegado a mero jogador inconsciente no jogo de entendimentos humanos.

No entanto, se pensarmos agência como ligada ao espírito e se pensarmos que o espírito existe em todas as coisas, então todas as coisas possuem agência. Nas palavras do ancião Fred Kelly, nossas histórias de origem declaram que a Mulher Céu era capaz de se comunicar com os animais e vice-versa. Nossa capacidade de ter sofisticados sistemas de governança está diretamente relacionada não só à capacidade dos animais em se comunicar conosco, mas à sua disposição em se comunicar conosco. Vine Deloria (2003) argumentou que todos os eventos humanos são referenciados à terra ou com terra na mente. Isso não se destina, por princípio, a ser estratégia política (embora funcione assim); em vez disso, é algo que todos temos como sagrado. Espírito está contido dentro de todos os elementos da natureza (SIOUI, 1992) e, portanto, nós, como humanos, sabemos que nossas ações são intrínseca e inseparavelmente ligadas à intencionalidade da terra - uma posição totalmente contrária a formulações diluídas da agência.

\section{Como a colonização operacionaliza agência}

O que acontece quando o solo é removido do território? O que acontece quando a carne é retirada do corpo? Mais importante ainda, o que acontece ao território depois que seus recursos são escavados? Shopping centers e fábricas de papel - uma escavação literal de pensamentos que são forçosamente transformados em objetos do imperativo colonial. Aquelas colheitas tornam-se as suas colheitas, aquelas árvores se tornam suas árvores e assim por diante, sucessivamente. Uma vez que as vozes e os pensamentos dessas duas categorias essenciais de criação (feminino e terra) são silenciadas e, em seguida, corrompidas, cumpre-se a aquisição e a destruição da terra.

De um ponto de vista teórico, o material (corpo/terra) torna-se abstraído em espaços epistemológicos como recurso para os estudiosos não indígenas implodirem suas fronteiras hegemônicas. Uma vez 
escavadas, a Primeira Mulher e todos os seus ensinamentos, ontologias e ações são interpretadas como folclore atraente e pontos de desempates teóricos para desmantelar e dissecar aquilo que oprime. Noël Sturgeon (1997) escreve:

No caso das mulheres nativas americanas não são necessários argumentos essencialistas, biologicamente deterministas sobre a conexão entre as mulheres e a natureza; em vez disso, suas tradições culturais e suas práticas econômicas podem ser vistas como criadoras de conexões positivas entre natureza e feminino, bem como entre natureza e masculino (STURGEON, 1997, p. 119).

No entanto, o que acontece quando maneiras indígenas de se relacionar com a terra são baseadas em uma conexão essencial e literal com o feminino? Será que isso significa que estamos nos entregando a estereótipos ou talvez sejamos ingênuas? Ou, pior ainda, estamos validando o centro por sermos reacionárias?

Smith (2005) descreve a violência contra terras indígenas e contra mulheres indígenas como sendo essencialmente ligadas uma à outra. As técnicas desta violência foram e são utilizadas pelos colonos como estratégias para governar povos indígenas (STOLER, 2002). Muitas sociedades indígenas, no momento do contato, eram matriarcais na composição, um ponto-chave da diferença cultural e política com a população colona inicial (SIOUI, 1992; MARACLE, 1996). A fim de ganhar acesso não apenas a territórios, mas também para facilitar a mudança na ordem interna das sociedades indígenas, as mulheres foram tanto utilizadas como um meio de infiltração nas estruturas sociais, quanto como objeto de subjugação violenta através do estupro, da remoção de crianças de casa (ou seja, escolas residenciais) e da morte (BRAND, 1981; SMITH, 2005). Esta evidência sugere que a "mulher indígena" foi igualmente necessária e problemática para o imperativo colonial, dado seu poderoso status em muitas sociedades indígenas.

A divisão epistemologia-ontologia desvia a agência para longe da terra e outros seres não humanos. Com essa concepção, a sociedade dominante na América do Norte aponta números desproporcionalmente elevados de mulheres indígenas nas prisões, como profissionais do sexo, as vítimas de violência física e sexual (SMITH, 2005). Ao mesmo 
tempo, a terra vem cada vez mais sendo escavada, redesenhada, dilacerada. Isso é apenas uma coincidência? Claro que não. Feminino e terra são fundamentais para nossas extensões como pessoas (GUNNALLEN, 1992). Então, em uma tentativa de conquistar essas pessoas, por onde você começaria? Por nossa terra e nossas mulheres, impossibilitando a comunicação com Lugar-Pensamento e implementando uma agência limitada onde as mulheres são subhumano/não humano. O colonialismo é operacionalizado através do desmantelamento das categorias essenciais de outras sociedades.

Além disso, os discursos euro-ocidentais têm muitas vezes tentado remediar os erros históricos de essencialismos biológicos (racismo científico) rejeitando o que são considerados argumentos essencialistas. Por exemplo, algumas escritoras indígenas foram acusadas de serem reacionárias ou ginocêntricas, implicando que elas estariam na borda de um essencialismo perigoso. No entanto, categorias essencializadas de cosmologias indígenas não devem ser medidas em relação aos produtos dos erros euro-ocidentais. Nem devem os povos indígenas ser os herdeiros desses erros. Em vez disso, para descolonizar ou acessar a mente pré-colonial, nossas histórias (não nosso folclore) devem ser entendidas em sua intenção original de nos permitir que sejamos verdadeiramente seres agentes. Desembaraçar-nos do essencialismo implica no risco de nos desembaraçarmos da terra.

\section{Mulher Céu e Primeira Mulher voltam para casa}

Como pessoas indígenas, a comunicação com Lugar-Pensamento (cerimônias com a terra, território, as quatro direções etc.) não é apenas uma obrigação, ela assegura nossa capacidade contínua de agir e pensar de acordo com nossas cosmologias. Evitar estas práticas nos ensurdece. Não é que o mundo não humano deixe de falar, mas nós passamos a compreendê-lo cada vez menos. É por isso que, apesar de quinhentos anos de colonialismo, nós ainda não estamos completamente colonizados e nós ainda continuamos a lutar; nós temos dentro de nós a capacidade de nos comunicarmos com a terra, mas a 
nossa agência como povos indígenas foi corrompida no interior da estrutura colonial.

A Figura 1.1 mostrou como cosmologias indígenas e a divisão euro-ocidental epistemologia-ontologia processam agência de forma diferente. Nossas cosmologias (e as teorias dentro delas) são rigorosamente diferentes e não podem ser separadas da matéria da natureza. Quando uma cosmologia indígena é traduzida através de um processo euro-ocidental, é necessária uma distinção entre lugar e pensamento. O resultado desta distinção é uma interpretação colonizada de ambos, local e pensamento, onde a terra é simplesmente pó e o pensamento é possuído apenas por humanos. Se operacionalizamos esta distinção, nós, como pessoas indígenas, nos arriscamos a desacreditar de nós mesmos. Mesmo entre nós pode ser fácil esquecer que a nossa capacidade de falar com a terra não é apenas um eco de um conto mítico ou parte de um código moral, mas uma realidade. Se esse esquecimento tem sido forçado sobre nós, ou se nossos ouvidos têm se aborrecido com os sons da terra falando através de nossos pés, agora nos compete relembrar. Isso não é uma questão de "andar para trás", porque isso implicaria a existência de um lugar estático para onde voltar. No entanto, dado que o conceito de tempo para nós nunca foi linear, nós possuímos a capacidade de acessar a mente pré-colonial através da capacidade de viajar em sonhos, de se metamorfosear para entender o que pode acontecer amanhã etc. Nossos ensinamentos nos dizem que viajamos através, por baixo, por cima. Então não é uma questão de acessar algo que já veio e se foi, mas simplesmente ouvir. Agir.

Espero que nesse artigo eu tenha enfatizado algumas das maneiras importantes nas quais obrigação e responsabilidade denotam um compromisso com a terra, não só porque ela é uma parte de mim (ou de você), mas também porque ela continua a ser removida, cimentada ou ignorada. Ouvir o que ela nos fala é não apenas sobre a compreensão filosófica da vida e do social, mas sim sobre uma violência tangível e tácita contra ela - e, portanto, contra nós. Espero que esta discussão possa levar a conversas sobre corpos em ação e sobre como carne arenosa é movida para proteger e reivindicar territórios.

Nós precisamos continuar a resistir à crescente tendência de 
sermos subsumidos em espaços epistemológicos dessencializados e lutar contra o deslocamento de lugar dos nossos pensamentos. Para esse fim, carne torna-se ação não porque ela é material, mas porque assim os ouvidos permanecem abertos e voltados para o chão. Somente se a terra decidir parar de falar conosco entraremos no mundo de deslocamento onde a agência está perdida e nossas histórias se tornam provocadores saberes indígenas no equívoco colonial ainda em curso. Felizmente para nós, a Primeira Mulher mostrou-se muito mais inteligente do que isso, escrevendo a si mesma em nossa carne.

\section{Referências bibliográficas}

ALAIMO, Stacy. Trans-corporeal feminisms and the ethical space of nature. In: ALAIMO, S.; HEKMAN, S. (Org.). Material feminisms. Bloomington: Indiana University Press, 2008. p. 237-264.

ALFRED, Taiaiake. Peace, power and righteousness. Ontario: Oxford University Press, 1999.

BENTON-BENAI, Edward. The Mishomis book. University of Minnesota Press, 2010.

BRAND, Johanna. The life and death of Anna Mae Aquash. Lorimer Publishers, 1993.

CAJETE, Gregory. Native science: natural laws of interdependence. Sante Fe: Clear Light Publishers, 2000.

DELORIA, Vine. God is red. USA: Fulcrum Publishing, 2003.

DESCARTES, René. Descartes: meditations on first philosophy: with selections from the objections and replies. Cambridge: Cambridge University Press, 1996.

EIKJOK, Jorunn. Gender, essentialism and feminism in Samiland. In: GREEN, J. (Org.). Making spaces for Indigenous feminisms. Winnipeg: Fernwood Publishing, 2007. p. 108-121.

GUNN-ALLEN, Paula. The sacred hoop. Beacon Press, 1992.

HARAWAY, Donna. Situated knowledges: the science question in feminism and the privilege of partial perspective. Feminist Studies, v. 14, n. 3, p. 575-599, 1988. 
The Haraway reader. New York: Routledge, 2004.

HILL, Susan. Storyteller's Conference. SUNY at Buffalo, 2012, March 26.

KANT, Immanuel. Critique of pure reason. Cambridge: Cambridge University Press, 1999.

KELLY, Fred. Anishnaabe leadership. Unpublished manuscript, 2005.

KIRBY, Vicky. Natural convers(at)ions: or what if culture was really nature all along? In: ALAIMO, S.; HEKMAN, S. (Org.). Material feminisms. Bloomington: Indiana University Press, 2008. p. 214-236.

LATOUR, Bruno. Science in action: how to follow scientists and engineers through society. Milton Keynes: Open University Press, 1987.

LOCKIE, Stewart. Collective agency, non-human causality and environmental social movements: a case study of the Australian 'Landcare Movement'. Journal of Sociology, v. 40, n. 1, p. 41-57, 2004.

MARACLE, Lee. I am woman. BC: Press Gang Publishers, 1996.

MOHAWK, John. Iroquois creation story. Mohawk Publications, 2005.

Thinking in Indian: Collected essays of John Mohawk. Canada: Fulcrum Publishing, 2010.

NASH, Linda. The agency of nature or the nature of agency? Environmental History, v. 10, n. 1, p. 67-69, 2005.

PESANTUBBEE, Michelene E. Beyond domesticity: choctaw women negotiating the tension between Choctaw culture and Protestantism (with new Introduction). In: KUGEL, R.; ELERVELD MURPHY, L. (Org.). Native women's history in eastern North America before 1900. University of Nebraska Press, 2007.

PESANTUBBEE, Michelene E. Choctaw women in a chaotic world: The clash of cultures in the colonial Southeast. Albuquerque: University of New Mexico Press, 2007.

SIMPSON, Leanne. Dancing on our Turtle's back. Arbeiter Ring Publishing, 2011.

SIOUI, Georges E. For an Amerindian autohistory. Montreal: McGill-Queen's University Press, 1992.

SMITH, Andrea. Conquest: Sexual violence and American Indian Genocide. Cambridge. MA: South End Press, 2005.

STOLER, Ann Laura. Carnal knowledge and imperial power: Race and the intimate in colonial rule. Berkeley: University of California Press, 2002. 
STURGEON, Noël. Ecofeminist natures: Race, gender, feminist theory and political action. New York: Routledge, 1997.

TRASK, Haunani-Kay. From a Native daughter: Colonialism and sovereignty in Hawai'i. Hawai'i: University of Hawai'i Press, 1999.

VENNE, Sharon H. Our elders understand our rights: Evolving international law regarding Indigenous peoples. Penticton, British Columbia: Theytus Books Ltd, 1998.

Recebido em: 04/04/2017 * Aprovado em: 30/05/2017 * Publicado em: 30/06/2017 